\title{
Antropología y Política. Varia epistemológica y prácticas intelectuales
}

\section{BREve y CANÓNICA historia de la ANTROPología Política}

La antropología política tiene unos orígenes canónicos extranamente muy precisos. De los manuales más conocidos de esta parcela del saber antropológico -Balandier, 1967; Lewellen ,1983; Vincent, 1990- se extrae que los primeros ancestros de la antropología política realizaron su producción entre 1861-1864, época de publicación de La cité antique de Fustel de Coulanges y Ancient Law de Henri Maine, y 1877, cuando sería editada Ancient Society de Lewis H. Morgan. Los tres autores realizaron apreciaciones sustanciales sobre la naturaleza de lo político, interrelacionando respectiva y dicotómicamente religión y política, ley y sistema político, y sistema tribal y emergencia del orden político. La política en ese lapso de tiempo, que transcurre en la segunda mitad del siglo xIX, en Europa y Norteamérica se está convirtiendo en una actividad profesionalizada, tras los flujos y reflujos revolucionarios, dado que además las viejas teorías de la filosofía política ilustrada, de un lado, y reaccionaria, de otro, se estaban quedando atrás en la interpretación de los graves acontecimientos contemporáneos. Añadámosle, que en el horizonte emerge una potente información etnográfica, cada vez de mayor volumen por el proceso de conquista territorial euroamericana, sea bajo la especie colonial o de la simple ocupación del espacio. Como consecuencia de ello tanto Fustel, como Maine y Morgan, se alejarán de la filosofía política de los modelos hasta entonces imperantes - Rousseau, Voltaire, Locke-, en la medida en que recurrían a la reconstrucción histórica, al comparativismo jurídico, y a la información etnológica recogida sobre el terreno.

El segundo momento epistémico transcurre entre 1927, momento de la aparición de The Origin of the State de Robert H. Lowie, y 1940, año de la publicación del coloquio sobre African Political Systems, coordinado por Evans E. Evans-Pritchard y Meyer Fortes. La primera obra tendría como referente la negación de la mirada evolucionista de Morgan en particular, y de los politólogos marxistas en general. Para Lowie, en toda sociedad, elemental o compleja, estaba en germen o en presencia contenido el poder político; de tal manera que no se trataba de contemplar el cuadro de las 
sociedades humanas dentro de una evolución desde las que carecían de Estado a las que lo tuviesen, para luego aspirar revolucionariamente a suprimirlo, como de entender que el poder político-estatal estaba en todo lugar. El compendio de Evans-Pritchard y Fortes, de otra parte, tuvo la virtud de poner en circulación para toda África la noción de segmentariedad, es decir la preeminencia de alianzas y conflictos entre segmentos de linajes parentales, que vendría a ser la trama sobre la que se asentaría el poder, tanto en las sociedades de jefatura como en las monarquías. Evans-Pritchard había publicado también en las mismas fechas su monografía sobre los Nuer del Sudán, en uno de cuyos capítulos se extendería sobre las nociones de segmentariedad y segmento. En definitiva, en esta época asistimos, por mor de acontecimientos políticos de repercusión universal - revolución rusa, guerras mundiales, época dorada del colonialismo- al surgimiento de debates de carácter antropológico orientados exclusiva o preferentemente hacia la comprensión de la política.

El período de consolidación de la antropología política como subdisciplina dentro de la antropología social se inicia en los años cincuenta, con la aparición de las obras de Max Gluckman sobre orden y rebelión en las sociedades tribales. Gluckman mantuvo una teoría de gran sencillez conceptual, empleando una metáfora casi orgánica: toma como punto de partida los rituales de rebelión contra los monarcas africanos, acusados por sus pueblos de decadencia física y social y por ello apartados del poder. Estos hechos los había popularizado James Frazer en la Rama Dorada y Evans-Pritchard, en un artículo sobre la monarquía shilluk, les había dado una explicación sociológica. Para Gluckman se trata sobre todo de rituales de rebelión que permiten restablecer el orden social que, no siendo igual al anterior a la rebelión, tampoco será radicalmente diferente. Su breve teoría, acompañada de un buen aparato etnográfico, obtuvo rápida fortuna, gracias a su personal incardinación profesional en las universidades británicas, donde ejerció el magisterio. La mayor de las críticas que recibió fue aquella que recordaba que sus investigaciones estaban fundadas en estudios realizados en territorios gobernados en última instancia por blancos sudafricanos, donde los conflictos internos no afloraban completamente.

Los siguientes debates tuvieron el sello de la continuidad evolucionista. La antropología marxista procuró adecuar las pocas líneas pergenadas por Marx y Engels sobre las sociedades precapitalistas con los nuevos conocimientos empíricos, validando el sentido evolutivo de las sociedades humanas hasta arribar a la cultura más desarrollada tecnológica y socialmente, previa al acceso del socialismo: el capitalismo. El debate sobre el modo de producción asiático, ampliado por Karl Wittfogel en los años 
cincuenta a la hidráulica, posiblemente sería el de mayor repercusión. Wittfogel sugirió que el Estado en su forma prístina apareció en aquellas sociedades dotadas de grandes recursos hídricos, y en consecuencia precisadas de acometer importantes obras públicas para la puesta en valor de las tierras agrícolas, lo que sólo podrían llevar a cabo poderes centralizados y despóticos. De otro lado, dentro del frágil territorio del marxismo académico, surgirá a partir de los años sesenta el empeño de, combinando datos procedentes de la arqueología y de la antropología de las sociedades elementales, trazar un completo cuadro evolutivo de la política. Este empeño, en el que la adecuación ecológica al territorio será presentada como infraestructural, corresponde sobre todo a un materialismo cultural., sencillo de explicar y adecuado a las demandas de sentido del gran público.

En cualquier caso, los trabajos más sólidos de investigación política por parte de antropólogos, de los años sesenta y setenta, provendrán de las contigüidades entre jerarquía/parentesco/política. Los estudios de Edmund Leach y Louis Dumont respecto a Birmania y la India, serán decisivos. Political Systems of Highland Burma de Leach, aparecido en 1964, confrontará la existencia de dos sistemas, uno igualitario y otro jerárquico, en una misma sociedad sometida a los avatares de la historia, al igual que las sociedades occidentales. En un sentido muy similar presenta a la sociedad de castas india, Louis Dumont en su obra Homo Hierarchicus. La tensión entre jerarquía e igualdad es fundamental para comprender la antropología política del futuro, la de hoy mismo.

Pero la historia de la antropología política, aquí esbozada de forma introductoria para dar paso a una visión transversal de su universo conceptual, no se agota en una historia de las ideas y debates surgidos en poco más de un siglo: es también, y así lo vamos a exponer, la historia de la relación entre antropología y política en el campo de la práctica social. Llevaremos, pues, la antropología del terreno aséptico del "saber", contemplado transversalmente, hasta el contaminado de las prácticas políticas de sus actantes.

\section{Mínimos antropológicos de la polftica}

Georges Balandier publicó en 1967 el primer manual de antropología política, que a su vez serviría de punto de arranque para la etnología política francesa, ya que hasta entonces esta subdisciplina había sido de adscripción mayoritariamente británica. Previamente al libro de Balandier, se habían conocido otros intentos de delimitar el nuevo saber emergente; 
así por ejemplo David Easton en 1959 había publicado un largo artículo, con comentarios a la bibliografía aparecida hasta entonces. Pero la Antbropologie Politique de Balandier tenía la virtud de no ser una mera historia, más o menos acertada, de la subdisciplina, era una salida a escena de sus principales problemas.

Uno de ellos era el de la propia naturaleza de la política, una vez separada del parentesco y de la religión. Para Balandier las concepciones epistemológicas de la política podían dividirse en "maximalistas" y "minimalistas". Los primeros autores otorgarían la categoría de "política" con una gran liberalidad, los segundos "se mostrarían negativos o ambigüos a otorgar la atribución de un gobierno a todas las sociedades primitivasn. Como subraya el mismo Balandier, "la ambigüedad se encuentra, a la vez, en los hechos, en las investigaciones y en el vocabulario técnico de los especialistas (...) El término 'política' comporta varias acepciones -las cuales son sugeridas por la lengua inglesa que diferencia 'polity', 'policy' y 'politics' (Balandier, 1991: 32).

Esa ambigüedad del lenguaje profesional empleado en antropología política podríamos extenderla a aspectos particulares de su campo teórico; así ocurría con el término burocracia, empleado por Lloyd A. Fallers para designar la estructura política bantú, o los de clientelismo y feudalismo, utilizados en los años setenta por diversos africanistas para polemizar sobre la naturaleza de las relaciones jerárquicas en África negra. Jack Goody se interrogaba a propósito de una de estas modas conceptuales: ‘¿Feudalismo en África?. Llegaba a la conclusión de que en África los teóricos que apuestan por ofrecer una visión clientelista y feudal de la política son deudores en buena medida del evolucionismo, y que por ello distorsionan la lógica sociopolítica (Goody, 1971: 1-20). Es un hecho reconocido que tras las palabras argotizadas suelen esconderse las más de las veces numerosas insuficiencias empíricas y teóricas. Así, para penetrar en el viejo problema de los límites de la política el primer ejercicio intelectual debiera partir del abandono previo del argot profesional; lo decía Marshall Sahlins hace no demasiados años: «El camino del progreso antropológico está sembrado de cadáveres terminológicos, la mayoría de cuyos espíritus es mejor evitar" (Sahlins, 1977: 108). Sólo algún que otro antropólogo, ha tenido la lucidez de evitar el fárrago de las clasificaciones y preguntarse lógicamente dónde está el umbral mínimo para que exista la política como tal.

En esa línea E. Terray se remite al historiador de la Antigüedad Moses Finley, quien subrayó que la mayor parte de las tomas de decisión en el mundo pre-político eran o bien asunto de un solo hombre, o bien se remitían al universo religioso por intermedio de los oráculos y del azar. 
"En tales sociedades (...) no hay política en el sentido propio de la palabra. La política surge como esfera específica en el seno de lo social cuando las decisiones que ligan al conjunto de los miembros de la comunidad son tomadas y más exactamente producidas por la discusión y el voto" (Terray, 1987: 720). Para Terray, por tanto, la política no es un universal; su mínimo es la existencia de debate, entendiendo por tal que los mecanismos de las tomas de decisiones sean colectivos al menos en sus fases preliminares. Tras el análisis de varios estudios sobre sociedades africanas concluye: "En realidad, las deliberaciones de los Estados africanos no se oponen a las ciudades griegas más que bajo un solo aspecto, pero el cual se puede admitir que es decisivo: los mecanismos de la decisión" (Terray, 1987: 728).

David Easton consideraba que la toma de decisiones se subordina a la resolución de conflictos, para hacer en definitiva "political community". En la resolución de conflictos se pondrían en juego tres factores: segmentariedad, liderazgo y competición. La segmentariedad como juego de alianzas y contraalianzas -fusiones y fisiones-; el liderazgo y la competición como acciones en la arena política (Easton, 1959). El concepto de arena política de todas maneras nos devuelve a la noción de "debate* de Terray, pero en un sentido más extenso, más estructural, puesto que no hay sólo "toma de decisiones", con el sentido consciente que se le otorga: hay también acción política estructuralmente inconsciente o semiconsciente.

La expresión .juegos, combates y políticas", acuñada por F. G. Bailey, identifica la actividad política con la competencia por el poder en la arena. La competición tomaría así un lugar estructural en la acción política, tras unos límites que deben impedir la destrucción de las personas. El control, según Bailey, de estas actividades competenciales vendría de las autoridades. "Las autoridades ideales -escribe- tendrían dos características: son neutrales entre los contendientes; y reciben su obediencian (Bailey, 1990: 32).

Lucy Mair combatió la identificación de la política con el Estado. No consideraba necesario que la organización política, como creía RadcliffeBrown, tuviese que ser confundida con una organización coercitiva. Prefirió emplear el término "gobierno" como unidad conceptual de organización política mínima. Escribió: "Un gobierno puede ser 'mínimo' por diferentes causas: comunidad política muy reducida (...); pocas posiciones de liderazgo reconocidas; escaso alcance de la autoridad o el liderazgo efectivo ejercido por quienes ocupan tales posiciones" (Mair, 1977: 63). Dentro de esa estructuración mínima de la política, L. Mair habló igualmente de "gobierno difuso", que identificó con una suerte de poder po- 
lítico ejercido colegiadamente por los grupos etarios - de edad- masculinos, :aunque puede haber entre ellos ciertos cargos que permitan ejercer autoridad sobre determinados puntos del sistema.

Dado que la política no puede ser definida tal que un absoluto, D. Easton prefería distinguir entre la política como actividad y las funciones políticas. Las funciones políticas, por regla general, serían ejercidas por asambleas - lo que demuestran concretamente los estudios realizados en África negra-, con lo que volvemos a la idea inicial de arena política, donde entran en competencia los intereses parentales, individuales y territoriales. Marc Abélès estudió este aspecto en las comunidades rurales de los Montes Gamo de Etiopía, de donde extrajo la siguiente ideal global:

El sistema político funciona en el seno de las subdivisiones residenciales. Las asambleas administran los asuntos de la colectividad, múltiples problemas son puestos allí en debate. Al lado de los litigios entre particulares a propósito de los límites de sus parcelas o de las querellas concernientes a las prioridades acordadas para el riego de las tierras bajas, las reuniones también tienen por objeto promover iniciativas colectivas: el arreglo de los caminos, la organización de los sacrificios, por ejemplo (Abélès, 1983: 43).

En un primer momento, pues, la política tiene que ver conceptualmente con la existencia del debate, de la "mise-à-scene" en la arena política, y esta con la toma de decisiones adoptadas de manera funcional y consciente. En general, gran parte de la antropología política y de la politología siguen empleando la idea de toma de decisiones en un sentido no sólo funcional sino "minimaln, en orden a definir la naturaleza de la política. A mediados los años sesenta David Easton después de comprobar la enorme aceptación que había tenido la teoría de la toma de decisiones decía:

Se adoptó formal y sistemáticamente para investigar la estructura y los procesos políticos de la comunidad, para comprender empíricamente las relaciones internacionales, y, en el nivel formal, para la lógica de la opción, expresada en la teoría de los juegos. A la par que ello sucedía, la investigación sobre las votaciones, bajo el estímulo de la psicología social, descubrió en el concepto decisional una matriz teórica para sí misma (Easton, 1969: 42).

Easton, previendo el esencialismo conceptual en el terreno de la política, de todas maneras, advertía acto seguido: -Los conceptos nunca son verdaderos ni falsos; son sólo más o menos útiles.. De alguna manera podemos enmarcar la más reciente teoría procesual, que pone el acento en alos objetivos asumidos por el grupo conscientemente* (Lewellen, 1985: 91), como una continuación lógica de la teoría de la toma de de- 
cisiones. Sigue privilegiándose en ella como marco mínimo la acción política consciente. La teoría procesual procedió inicialmente contra cierta antropología jurídica que estaba fijada sobremanera en las leyes y prestaba poca atención a los individuos como sujetos políticos. Los primeros teóricos de la procesualidad procuraron, de todas maneras, evitar el exceso de consciencia en la política, distinguiendo entre "tecnología. y efunciones sociales" en el ámbito de ésta: "El modelo de las fases sucesivas del proceso político depende de la tecnología disponible culturalmente y de las funciones que han sido institucionalizadas en el corazón del sistema político" (Winckler, 1969: 330).

Sobre la arena política competencial, tomada como unidad mínima política se ponen en acción, no sólo procesos desencadenados en la estructura política, sino pura y simplemente en la estructura, incorporando a ésta variables sociales, parentales, psicológicas, económicas, históricas, amén de estrictamente políticas.

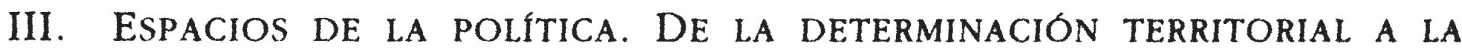
CONTIGÜIDAD ELECTIVA

Seguramente los dos asuntos de mayor relevancia para el estudio de la política desde los inicios del pensamiento antropológico serían, por contraste con el punto anterior, no tanto la teoría consciente de la acción política, como los elementos estructurales, objetivos, ajenos a la intervención consciente y planificada de los individuos. El territorio y el parentesco determinarán esa lógica.

La consolidación de los Estados-nación en la misma época en que comienza a desarrollarse la antropología seguramente forzará su forma de acercarse al territorio como espacio acotado política y cognitivamente. Pierre R. Baduel lo mostró en los siguientes términos: el Estado-nación surge sobre basamentos territoriales; éstos a su vez son desprovistos de su condición religiosa y adquieren una dimensión propiamente política, gracias al trabajo teórico de la filosofía política ilustrada (Baduel, 1991). De ahí que los primeros antropólogos tengan una gran preocupación por las formas de organización política de fundamento territorial. Lewis H. Morgan lo subrayó en The Ancient Society:

La primera y más antigua, fue una organización social, asentada sobre las gentes, fratrías y tribus. La segunda y posterior en tiempo, fue una organización política, afirmada sobre territorio y propiedad. Bajo la primera, se creaba una sociedad gentilicia, en la que el gobiemo actuaba sobre las personas por medio de relaciones de gens o tribu. Estas relaciones eran puramente personales. Bajo la segunda se 
instituía una sociedad política, en la que el gobierno actuaba sobre las personas a través de relaciones territoriales, por ejemplo: el pueblo, el distrito y el estado (Morgan, 1975: 127).

Esta preocupación territorial se extenderá hasta Evans-Pritchard, el cual en la misma lógica morganiana, se preguntaba por el nexo de unión entre los Nuer, quienes se consideraban a sí mismos un "pueblo" aunque no existiesen entre ellos lazos estables, y su sistema político fuese similar a la confederación iroquesa estudiada por Morgan.

Todos los antropólogos y protoantropólogos de primera hora -Morgan, Maine, Fustel, Masqueray - aceptan o bien la hegemonía o bien dan un importante papel al principio de la territorialidad en la constitución de la sociedad política. En lo que difieren, y sobre lo que en definitiva establecerán la confrontación teórica, será en la importancia y/o precedencia de los lazos parentales. R. Lowie, radicalmente opuesto al evolucionismo de Morgan, arguye que el Estado en cuanto poder territorial es universal. "Introduciendo la noción de 'gérmenes', Lowie rehusa poner como exteriores a la política las causas de la aparición del Estado. Y esto porque él postula, al menos implícitamente, que la sociedad arcaica está dada desde los orígenes como política de parte a parte" (Abélès, 1990: 49). No niega que el parentesco y la organización territorial sean diferenciables, subrayando que ula solidez de la posición adoptada por Maine y Morgan al trazar una marcada distinción entre organización del parentesco (tribal) y territorial (política) es incuestionable». La gran diferencia con las posiciones de Morgan y Maine la cifra Lowie en el principio de contigüidad, que lleva más allá de la contigüidad parental: "Lo que importa -diráes que, incluso en niveles culturales muy modestos, la contigüidad es uno de los elementos determinantes de la solidaridad social, con independencia de la relación consanguínea" (Lowie, 1979: 271). Las asociaciones voluntarias y los grupos etarios aparecen en el horizonte como algunas de las vías de formación del poder político, cuyo origen reside en la contigüidad.

Georges Balandier señaló que en las sociedades africanas tradicionales los grupos etarios, de edad, juegan un papel central en la conformación del poder político. Siendo las "clases de edad" una forma de clasificación más sociológica que de tiempo físico, "la 'edad social' se convierte de esta manera en el gran principio organizador de estas sociedades" (Balandier, 1975: 71). Otro tanto cabe decir de las asociaciones voluntarias, derivadas de sociedades de iniciación tradicionales o importadas conforme a modelos europeos, como grupos de intervención política de creciente importancia. Desde los mau mau hasta la francmasonería, opus dei, etc. constituyen vehículos de poder no transparentes, sin cuya concurrencia no puede 
comprenderse la naturaleza del poder político hoy. Esos grupos sociales se han liberado de las ataduras del principio de territorialidad, se hallan en el de la contigüidad y procuran operar en el de la toma de decisiones.

El parentesco, segundo componente de los debates iniciales de la antropología política, debe ser contemplado bajo dos sistemas, el de las estructuras elementales y el de las complejas. En las elementales el matrimonio tendría una orientación prescriptiva en relación con el parentesco. La base de la prescripción matrimonial residiría en la prohibición universal del incesto, concebida como una regla o conjunto de reglas de orientación, que permitiría la existencia del grupo humano. "El papel primordial de la cultura -escribe Lévi-Strauss- es asegurar la existencia del grupo como grupo y, por lo tanto, sustituir en este dominio, como en todos los demás, el azar por la organización. La prohibición del incesto constituye cierta forma -y hasta formas muy diversas - de intervención. (Lévi-Strauss, 1981: 68). La prescripción familiar aparece estructural e inconsciente, ajena a las voluntades individuales. El parentesco, en las sociedades elementales se asemejaría a una estructura lógico-matemática. Y estaría, en buena lógica, en las antípodas del proceso de toma de decisiones.

En el estadio del tránsito a las sociedades complejas el matrimonio se transforma de prescriptivo en preferencial. Ahora el grado de aleatoriedad de las relaciones de parentesco es infinitamente mayor. Los caracteres del matrimonio moderno de las sociedades complejas, según Lévi-Strauss, serían: "La libertad de elección del cónyuge dentro del límite de los grados prohibidos, la igualdad de los sexos frente a los votos conyugales y, por fin, la emancipación de la parentela y la individualización del contrato* (Lévi-Strauss, 1981: 554). La voluntad, la toma de decisiones, aparece ahora central en el sistema parental.

Las tesis anteriores sobre el parentesco tienen una gran importancia para la antropología política, ya que una de las principales preocupaciones de los primeros etnólogos, como Lewis H. Morgan, estuvo en la dilucidación del umbral en que el parentesco dejaba de ser operativo como núcleo principal o exclusivo de organización social y, emancipada de él en parte la estructura social, se pasaba al estadio político. El ejemplo más elocuente que expone Morgan es el de la confederación iroquesa, de la que dice que se formó como "testimonio de su capacidad superior"; gracias a esa capacidad los iroqueses se habían dotado políticamente de un Consejo General de sachems limitado en número, iguales en rango y autoridad, e investido de supremas facultades para todo lo concerniente a la confederación. (Morgan, 1975: 183). El tránsito de la tribu a la confederación se presenta como el umbral de la organización política, el punto de arranque de la arena política competencial. 
El problema surge en relación con el modelo de transformaciones parentales, tribales y territoriales que dan lugar a la confederación. Aquí justamente emerge de la mano de Evans-Pritchard la idea de segmentariedad; éste había definido los segmentos de la tribu como núcleos sociales plenos con muchas de las características de las unidades tribales. -Cada uno de los segmentos - dirá- tiene su nombre distintivo, su sentimiento común y su territorio únicon. El principio de fusión, y fusión bajo la hegemonía de la alianza, está presidido por la siguiente combinatoria: “Cada segmento está segmentado, a su vez, y existe oposición entre sus partes. Los miembros de cada segmento se unen para la guerra contra los segmentos adyacentes del mismo orden y se unen con dichos segmentos adyacentes contra secciones mayores" (Evans-Pritchard, 1977: 164). Balandier consideró adecuadamente que del principio de segmentariedad se extraía que "el poder y el parentesco están en relación dialéctica, de donde escapan a toda interpretación unilateral. (Balandier, 1991: 91).

Uno de los terrenos privilegiados para el estudio de la segmentariedad y su vínculo con el poder político, serán los grupos sociales beréberes del Rif norteafricano. Desde muy temprano, en particular desde 1885 en que fuera publicada la obra de Émile Masqueray, la preocupación por la segmentariedad ha ido en aumento. Masqueray se interrogó por la estructura jurídico-política de los kabileños argelinos que, sin poseer ciudades propiamente dichas, tenían, no obstante, estructuras políticas estables; eran auténticas "ciudades" en el sentido político, aún no teniendo siquiera estructura urbana (Masqueray, 1983). Medio siglo después de Masqueray, otro etnógrafo, Robert Montagne señalaba la pervivencia en el Rif oriental de una situación similar:

Una de las características más destacables de la organización social bereber es la existencia de una jerarquía de pequeños estados, desde el cantón o la fracción de tribu o hasta la confederación; otra es la estructura de alianzas que los une por un proceso de coalición y oposición, para formar bloques de un tipo muy particular (Montagne, 1973: 45).

Más recientemente, uno de los mayores especialistas sobre segmentariedad norteafricana ha admitido que el modelo segmentario sigue siendo válido para explicar la organización sociopolítica bereber, aunque muestre algunas insuficiencias: -Tenemos que admitir que este paradigma ha llegado a ser un modelo ideal-típico, que en bastantes, o en muchos, casos concretos estaba contravenido por la realidad de los hechos* (Hart, 1994: 9). El mismo Hart, amén de otros autores como R. Jamous, ha subrayado el valor simbólico de la tierra entre los beréberes; el encabalgamiento de 
tierra y parentesco permite explicar el principio de la segmentariedad a la vez sobre bases espaciales y parentales. La herencia, el sistema de transmisión parental de la propiedad de la tierra, permite la cristalización de la segmentariedad (Hart, 1976: 91 y ss.).

Con la segmentariedad hemos vuelto al inicio de este parágrafo: la importancia del espacio territorial para la comprensión de la organización política, cualquiera que sea su formulación, como Estado, como ciudad, como confederación o como tribu, por sólo citar los estadios más recurrentes. Una última observación: la determinación territorial da paso a la contigüidad electiva en lo referente a la acción política, en la medida en que la sociedad transforma sus vínculos parentales y sociales de prescriptivos en preferenciales. Actualmente, con la mundialización de las relaciones de poder político, los espacios de la política se han emancipado decididamente en favor de la contigüidad electiva desterritorializada. Hoy, Lowie triunfa sobre Morgan en lo tocante a la comprensión de los espacios de la política.

IV. TIEMPOS DE LA POLITICA. UNA ANTIGUA CUESTIÓN: LA EVOLUCIÓN POLITICA DE LA SOCIEDAD Y LA APARICIÓN DEL ESTADO

En la mirada canónica de la antropología política, especialmente de la norteamericana, ha prevalecido la percepción evolucionista hasta el mismo día de hoy. Lógicamente, el esquema evolutivo de Morgan, vulgarizado por F. Engels, que contemplaba una acumulación cuantitativa en las causas y cualitativa en los efectos y que transcurría del salvajismo a las sociedades políticamente desarrolladas $\longrightarrow$ del "sin" al "con" Estado-, ha perdido adeptos, con seguridad por su simplicidad instrumental.

De todas maneras, el determinismo sociológico lleva a un grupo influyente de antropólogos norteamericanos en la órbita del materialismo cultural (suerte de sustituto del marxismo académico) a proponer nuevas lecturas sobre la evolución lineal desde las sociedades igualitarias a las civilizaciones. La cercanía académica de la arqueología a la antropología en las universidades estadounidenses ha permitido que el debate, enriquecido en orden a los datos empíricos y a las conceptualizaciones, haya sobrevivido. El punto de partida sigue siendo el mismo de toda la filosofía de la Ilustración, que a su vez sirviera de nutriente al evolucionismo: la progresión temporal de lo simple a lo complejo. Escribió E. Service:

La línea divisoria en la evolución de la cultura humana se dio cuando la sociedad primitiva se convirtió en sociedad civilizada. Como sabemos por los 
modernos estudios antropológicos, las sociedades primitivas estaban segmentadas en grupos de parentesco que eran igualitarios en sus relaciones mutuas. Eventualmente, algunos de ellos devinieron jerárquicos, controlados y dirigidos por un poder central autoritario (Service, 1984: 21-22).

La innovación de aquellos autores que, como el Marshall Sahlins preestructuralista o el citado Elman R. Service, apostaron por un evolucionismo renovado, estuvo en la crítica a quienes, siguiendo sobre todo al arqueólogo V. Gordon Childe, consideraban que el inicio del cambio cultural fundamental que dio paso al estadio de civilización fue la "revolución urbana" acontecida en el Neolítico mediterráneo-mesopotámico. Según los datos aportados por Service, "aunque en algunas de las civilizaciones arcaicas se encontró un cierto número de centros urbanos, éstos parecen no sólo no haber sido esenciales para el desarrollo de dichas civilizaciones, sino también haber sido, con enorme frecuencia, claramente dependientes de la primera evolución de las mismas" (Service, 1984: 26). Los conceptos de liderazgo, consenso, refuerzo del poder, etc. incorporados al conocimiento evolutivo, han dejado parcialmente atrás las ideas de Gordon Childe, si bien este autor procuró alejarse de un evolucionismo estrecho al apostar indirectamente por el difusionismo: " $\mathrm{Si}$ los objetos materiales pueden difundirse así -escribió-, igual pueden hacerlo las ideas (...) los evolucionistas nunca negaron este hecho, puesto que la 'evolución' no pretende describir el mecanismo del cambio cultural" (Gordon Childe, 1965: 25). Este es un aspecto que frecuentemente dejan de lado los neoevolucionistas al querer explicar, tras los mecanismos internos de la evolución cultural, la propia naturaleza del cambio.

Pero el criptomarxismo del materialismo cultural se queda corto ante la apuesta evolucionista de los antropólogos marxistas declarados. Maurice Godelier en 1968, cuando se empezaba a considerar viable la conjunción entre el materialismo histórico y la antropología social, expresó la siguiente opinión:

El marxismo no puede pues retomar los postulados del evolucionismo del siglo $\mathrm{xIX}$, incluso si reconoce el hecho fundamental de la evolución de la Naturaleza a la Sociedad. Los esquemas de evolución esbozados en nuestros días tropiezan con una dificultad suplementaria que Morgan no conocía. La clasificación de los sistemas de parentesco entre patrilineales y matrilineales no corresponde sino a los sistemas unilineales. La etnología moderna ha revelado la existencia y la frecuencia, al lado de aquellos, de sistemas bilineales y no lineales (Godelier, 1969: 144).

Esta negación del evolucionismo sociopolítico será de facto para afirmarlo posteriormente con nuevos recursos intelectuales, entre los que se 
encuentra el tránsito de unos sistemas de parentesco a otros; por esto señalaría Godelier acto seguido: "El problema de la evolución de las relaciones de parentesco sigue pues abierto». Su evolucionismo era definitivo.

Frente a la temporalidad evolucionista se alzaría el ahistoricismo funcionalista, como rasgo distintivo de la política vista desde la antropología social. La aparición de Political Systems of Highland Burma de Edmund Leach vendría a romper tanto con el ahistoricismo funcionalista, que sólo presentaba las sociedades en su estabilidad atemporal, como con la temporalidad evolucionista, observada precisamente tras la combinatoria de estructuras del parentesco y políticas. En la diferenciación de estructuras políticas y parentales que Leach establece entre los Kachim birmanos, hallamos el sistema "gumlao" y el "gumsan: el primero sería "una especie de organización 'democrática' en que la entidad política es la aldea individual y no existen diferencias de clase entre aristócratas y plebeyos"; el segundo, correspondería a "una organización 'aristocrática'" (Leach, 1976: 79). Ambos sistemas pertenecen a momentos históricos distintos de la sociedad kachim. "Cualquier teoría sobre el cambio social es necesariamente una teoría sobre el proceso histórico", dijo Leach como conclusión de su estudio. La aparición de las estructuras del parentesco, en apariencia atemporales, en el interior de los sistemas políticos había devuelto paradójicamente estas sociedades a la historia, no como un proceso unilineal, sino como un procedimiento de "bricolage entre nuevas estructuras y estructuras supervivientes. El tiempo de la política vuelve a estar en la intersección entre la diacronía y la sincronía.

\section{Conflictos de la política. Del equilibrio a la violencia organizada}

El ahistoricismo funcionalista en el campo del estudio de la política tuvo su máximo exponente en Max Gluckman quien, aunque no lograse un gran alcance teórico con su obra, tuvo la virtud de sintetizar y poner en circulación la noción de equilibrio. Según su experiencia etnográfica en África:

La gente no tendría idea de ningún otro sistema político más que aquel bajo el que viven, y no tendrían divisiones de clase productoras de revoluciones, dirigidas a generar diferentes tipos de orden social. Los conflictos surgidos en la nación sobre la actuación de los reyes y sus intromisiones en los derechos de los sujetos, mientras están dirigidos por lealtades institucionales y alianzas dentro de un sistema político soportan su reinado y el de la familia real. Durante un período de tiempo la cohesión del sistema absorbió los conflictos que el propio sistema generó (Gluckman, 1956: 43-44). 
La teoría del equilibrio explicaba bien la tendencia centrípeta de los sistemas políticos, frente a los movimientos centrífugos; pero en su desfavor militaba la visión excesivamente *armónica" que ofrecía de dichos sistemas. A Gluckman se le acusó de haberse basado en trabajos de campo realizados en Zululandia, una zona de apartheid., donde los conflictos internos no aparecían en plenitud por la dependencia última del poder de los blancos sudafricanos. Otros autores, de procedencia americana, y por tanto menos vinculados políticamente a los acontecimientos africanos del período colonial, pudieron ofrecer una visión de conflicto y cambio en lugar de "orden y rebelión", en el paso de los sistemas tradicionales a los sincréticos del poscolonialismo (Fallers, 1965).

B. Malinowski, previamente, había considerado que en las sociedades primitivas existen las mismas funciones políticas que en las sociedades occidentales: legislativa, judicial y ejecutiva. Las sociedades primitivas se diferenciaban en que las funciones estarían implícitas en la costumbre, y no explícitas en la distribución del poder estatal como en Occidente. Uno de los factores claves de la costumbre sería la unanimidad de la opinión colectiva para sancionar los actos sociales anómicos. Con posterioridad a Malinowski, se ha aventurado que la resolución de los conflictos en la sociedad puede obtenerse por dos vías, la del consenso y la del mecanismo mayorías/minorías. Sobre la del consenso existe toda una mística, que representa el mundo de las comunidades como un todo armónico, aunque según demostró F. G. Bailey para los casos de la India e Inglaterra, la mayor parte de las veces sus artífices sean una minoría aristocrática. De otro lado, sería posible el juego de las mayorías y minorías donde efectivamente funcionase la arena política (Bailey, 1965).

La lógica segmentaria, de facción, parece imponerse en las sociedades igualitarias, mientras en las aristocráticas prevalece el consenso. Pierre Clastres, tomando como modelo a los Yanomamo venezolanos, pudo verificar que el principio actuante en este tipo de sociedades es el hobbesiano, precisamente por su cercanía al estado igualitario. La visión de la violencia que solía ofrecerse por parte de los antropólogos era la de una agresión controlada; si Napoleon Chagnon había escandalizado a buena parte de la comunidad antropológica ofreciendo una imagen efiera. de los Yanomamo en los años sesenta, esa imagen la corregiría en parte en las últimas ediciones de su obra, al sostener que existen mecanismos rituales de control sobre la violencia yanomamo (Chagnon, 1992: 183-84). Pero a diferencia del resto de los etnólogos, y del propio Chagnon de hoy, Clastres asume la sfiereza. yanomamo como un rasgo distintivo de su libertad: :La voluntad de independencia política y el dominio exclusivo de su territorio manifestado por cada comunidad, la posibilidad de la guerra 
está inmediatamente inscrita en el funcionamiento de estas sociedades: la sociedad primitiva es el lugar del estado de guerra permanente. (Clastres, 1987: 207). La guerra, según Clastres, antecede a las alianzas y a la segmentariedad, aunque todas ellas estén íntimamente encabalgadas. No existiría, por tanto, estado de equilibrio sino estado de guerra segmentaria.

Edmund Leach en una conferencia pronunciada en la Universidad de Edimburgo en 1977 abordó un asunto por entonces de plena actualidad: la violencia política terrorista. Su acercamiento partía de una reflexión inicial sobre la visión malinowskiana de la ley y la costumbre. Recordó que en otras sociedades las transgresiones normativas son castigadas por la sociedad y/o la divinidad y que, sin embargo, en la moderna sociedad capitalista aquéllas suponen un ataque contra la sacralidad de la vida individual y la sacralidad de la propiedad" (Leach, 1977: 32). La aparición de la violencia política ciega, de todas formas, desató asimismo mecanismos de conservación social; MacFarlane lo ha subrayado para las comunidades en conflicto de Irlanda del Norte, quienes en el terreno de lo simbólico suelen negar la existencia de violencia, aunque ésta sea constatable empíricamente (MacFarlane, 1988). En el lado opuesto, una comunidad educada en la no violencia, al modo de la tahitiana donde la etiqueta social está orientada a la sublimación de los comportamientos agresivos, sólo permite la aparición de éstos cuando alcanzan significación política; J. Baré lo expuso en relación con varios conflictos acaecidos en Papeete, cuya característica común era que constituían expresiones de anticolonialismo o de luchas por puestos políticos en el gobierno municipal (Baré, 1984).

Si considerásemos con D. Gilmore, que la violencia y la agresión son factores de cohesión social, que hacen de las sociedades humanas un conjunto unido tras la sanción y punición individual y colectiva (Gilmore, 1983), podríamos considerar la violencia política como un mecanismo de identidad más efectivo simbólicamente que cualquier otro; de ahí la facilidad con que aflora en la arena política cuando ésta alcanza niveles agonísticos. En el lado contrario, suele ocurrir que una sociedad que haya sufrido en alto grado la violencia política, como la andaluza durante la guerra civil de 1936-39, procure rehuirla, tal como señala Gilmore, movida por un auténtico terror pánico a la violencia física, y que en consecuencia acabe desviando los mecanismos de la agresión hacia campos tangenciales a la política: la fiesta, la murmuración, los apodos, etc. La violencia política es, pues, la clave simbólica tanto de la fusión identitaria social como de la fisión segmentaria. Así ocurre en el País Vasco donde la violencia terrorista, ejercida a través de las ekinzak. (acciones), es una suerte de "comunión mística. al decir de J. Zulaika; lo mismo que la quema de 
conventos lo fue en la Barcelona de los años treinta (Zulaika, 1990; Delgado, 1993).

En todo caso y lugar, la máxima expresión de la agresión es la violencia política. Dentro de ésta ha tomado carta de naturaleza específica el terrorismo político; como señala Julio Caro, el empleo de la palabra terror aplicado a la política tiene su inicio en los momentos más virulentos de la Revolución francesa; el terror empleado con intencionalidad política tuvo allí su nacimiento conceptual (Caro Baroja, 1989). En una revolución, como la francesa, de total intencionalidad política.

\section{Ritológicas de la política. Del liderazgo a la monarQuía}

Coexisten en antropología dos formas de entender la política, no contrapuestas pero sí diferenciables en términos analíticos: la que atiende sobre todo al análisis del grupo y de sus mecanismos sociales en cuanto tales; y la que pone el acento en la formación y manipulación consciente y/o inconsciente de los símbolos políticos. Esta diferenciación está atravesada por la noción de estructura social, extraída del pensamiento de Radcliffe-Brown, que posteriormente sería corregida por Lévi-Strauss extendiendo la noción de estructura a todos los órdenes de la cultura humana. La causalidad directa entre estructura social y función simbólica establecida por el funcionalismo radcliffe-browniano desaparecería en la medida en que las estructuras simbólicas acceden a una autonomía plena, a una lógica propia sin relación inmediata con la vida social.

El primer aspecto, el más cercano a la estructura social y a la reproducción política, sería el liderazgo. La aparición de un líder tiene que ver ante todo con la persistencia de la jerarquía y con la génesis del carisma. Bailey distinguió entre líderes clientelares y líderes morales, que de alguna manera, pueden corresponderse con esos dos conceptos. Ambos, sin embargo, no se hallan alejados el uno del otro; hoy sabemos, por ejemplo, que los caciques de la Restauración española ejercían no sólo la autoridad y la coerción subsiguiente sino también, en una buena parte de los casos, el liderazgo moral de la comunidad. Louis Dumont estableció los rasgos del "homo hierarchicus", como una suerte de combinación de rasgos de preeminencia parental, sanción religiosa y acción política (Dumont, 1970). El carisma, estudiado tempranamente por Max Weber, añade a lo anterior, según Ch. Lindholm, capacidades tales como el adecuado empleo de la oratoria y de la persuasión (Lindholm, 1992). A esto último habría que añadirle, al modo de ver de Bailey, el papel de intermediación de los líderes; Hassan Rachik, y otros autores que estudiaron la resolución de 
conflictos en el Magreb, comprobaron que en los líderes políticos y religiosos se combinan jerarquía y carisma para ejercer la intermediación (Rachik, 1992). Los linajes de santos representan esa conjunción en la mayoría de las ocasiones.

La formulación histórica del liderazgo depende del tipo de sociedad, amén del rito político anexo de confirmación pública de aquella función directriz. En las sociedades más elementales el liderazgo suele estar asociado al uso de la fuerza, e incluso a la belleza física. La complejidad que otorga la segmentariedad a las sociedades tribales convierte a los líderes de éstas en productos de varias estructuras, entre las que hay que subrayar las parentales, las jerarquías de edad, el honor y la posesión o usufructo de los recursos naturales. El líder arrastra consigo una facción, fundada generalmente en el vínculo clientelar que se establece entre él y sus seguidores. En opinión de R. W. Nicholas: $E l$ líder que es responsable de organizar el personal de una facción es ordinariamente un hombre con más poder político que algunos de sus seguidores" (Nicholas, 1965: 29).

Las capacidades oratorias no corresponden sólo a la voluntad de los individuos. La posibilidad de hablar en público y la legitimidad para hacerlo corresponden al mundo de las sanciones sociales. Según Maurice Bloch, el lenguaje no es sólo una cadena lógica sintáctica y morfológica: está subordinado semánticamente al contexto, entendido éste como las formas de dicción, la gestualidad, la intencionalidad comunicativa, etc. Para Bloch, que estudió esta fenomenología en la arena política de una comunidad de Madagascar, el lenguaje del poder está más formalizado, y en definitiva más empobrecido lingüísticamente, que el lenguaje spopular"; sin embargo posee una ambigüedad interna que refuerza su eficacia (Bloch, 1975). El hieratismo de la lengua del poder la acerca, al decir de Bloch, a la formalidad de la escritura, concebida tradicionalmente como vehículo de autoridad política y sacerdotal. Las tesis de Bloch coinciden con las de Mijail Baijtin sobre la espontaneidad del lenguaje popular, cercano al mundo carnavalesco, y en permanente confrontación con los lenguajes del poder.

La monarquía constituye uno de los sistemas más atractivos de abordar analíticamente desde la antropología política, seguramente por la alta fijación de su etiqueta y por el corpus" teórico-político que la acompaña. Kantorowicz estudió la minucia teológica y jurídica que conllevaba la teoría monárquica en la Inglaterra del tránsito de la Baja Edad Media al Renacimiento; el desdoblamiento en "cuerpo místico-político" y "cuerpo físico-ritual. resulta significativo para vislumbrar el grado de elaboración cultural de la institución monárquica (Kantorowicz, 1985). La etiqueta ritual no fue inicialmente uno de los temas más tratados por la antropología 
política; de hecho son poquísimos los estudios etnográficos sobre la etiqueta. E. Norbeck la expuso respecto a Hawai y el Japón: “Una distintiva categoría de roles de etiqueta tiene una especial significación funcional como sanción de los modos de autoridad. Estas reglas del comportamiento dadas entre desiguales sociales, estaban expresadas por tabús. Pueden ser razonablemente vistas como reglas de etiqueta a las cuales se les unen sanciones sobrenaturales" (Norbeck, 1977: 73). Algunos sistemas monárquicos han sido más proclives a la reificación ritual; es el caso de los Austrias españoles, estudiados por Carmelo Lisón Tolosana. El ritual austria, complicado y grandemente estático, responde casi a un ideario teocrático (Lisón Tolosana, 1991).

Los rituales de la realeza aparecen fijados en torno a determinados objetos, tal que la silla ceremonial entre los Akan de Costa de Marfil (Cannadine y Price, 1987). Pero el poder ritual de la monarquía funciona más en las estructuras del pensamiento que el mundo objetual que le sirve de soporte. Toda una corriente de pensamiento estructuralista ligada a C. Lévi-Strauss ha retomado uno de los primeros debates que inician la antropología política, el que estableciera James Frazer en La Rama Dorada al asociar las monarquías africanas, y la finitud política de sus reyes, a la vitalidad social. Bien es conocido que Evans-Pritchard en un célebre artículo sobre la monarquía shilluk, sistema político en el que era observable el fenómeno descrito por Frazer, sostuvo que la capacidad de liderazgo social de los reyes africanos tenía un carácter más funcional que místico. En época más reciente, Luc de Heusch, tras analizar las transformaciones internas de varios mitos bantúes relacionados con las monarquías africanas, ha retomado el punto de partida frazeriano (Heusch, 1972). Del terreno estricto de las mitologías proceden las aportaciones de G. Dumézil, quien estudiara la formación mitopoiética de las monarquías indoeuropeas. Gomes de Silva ha partido de la teoría frazeriana y de las aportaciones de Dumézil para interpretar el conjunto de las monarquías africanas (Gomes de Silva, 1987). La combinatoria de investigación mitológica y comparación etnográfica lleva a estos autores a penetrar en el campo ya abordado por la antropología filosófica sobre los fundamentos puramente abstractos del "mito del estado" (Cassirer, 1985).

La menor ritualización de los sistemas republicanos o monárquicos constitucionales contemporáneos, que para los efectos teóricos funcionan de forma similar, no ha impedido el análisis de sus componentes rituales, circunscritos en la mayoría de los casos a las maneras de aparición de los individuos en la arena política competencial. Tanto el sistema norteamericano como el francés, ambos republicanos en sentido estricto, han sido sometidos a un tipo de análisis que pone grandemente el acento en la 
teatralidad de la "mise-à-scene" política, y en la importancia de la manipulación de los códigos simbólicos, como factores claves para lograr el éxito en la lucha por el liderazgo faccional o social (Kertzer, 1988; Abélès, 1990). Las puestas en escena de F. Mitterrand o de los senadores norteamericanos responden a una cuidada escenografía de la manipulación de los códigos simbólicos. Así Mitterrand, según M. Abélès, anualmente realiza uno o dos actos en la Francia interior que sirven de recordatorio de la sliaisson" existente entre el presidente jacobino y la Francia periférica girondina; actos de renovación, en definitiva, del contrato político entre el mundo urbano y el rural francés, plenos de sentido histórico.

Cualquiera de las fórmulas aquí reseñadas - liderazgo, oratoria y monarquía - se constituyen en mediadores culturales - personales, lingüísticos e institucionales- entre la sociedad humana y el universo político. El liderazgo y la oratoria pueden constituirse en actividades políticas o no, dependiendo de la existencia de arena política competencial. La monarquía es un intermediador mucho más restringido; en ella la acción política y su correspondiente arena, están subordinadas a la etiqueta y el protocolo.

VII. PRácticas polfticas de la aNTROPOlOGía. De las polémicas aCadémicas Y SU ESCASA REPERCUSIÓN EN ESPAÑa

Posiblemente la antropología sea uno de los saberes sociales más politizados, cuestión que con frecuencia suele eludirse en las historias de la disciplina en circulación. El único debate político que le tocó de lleno, y a ciencia cierta la dejó estigmatizada, fue el del colonialismo. Se la identificó con el avance colonial decimonónico, y con sus necesidades funcionales de conocimiento de los pueblos extraeuropeos para mejor gobernarlos, bien a través del sistema de gobierno indirecto, promovido por Gran Bretaña, bien por el de la asimilación, extendido por Francia. Hubo, por parte de los antropólogos de pensamiento izquierdista, la intención de contribuir a la liberación de aquellos pueblos que la antropología se suponía había ayudado a dominar. Se repetía con facilidad escolar: -Anthropology is a child of Western imperialism. (Huizer, 1979). Y de ahí surgieron diferentes propuestas de reconducción del saber antropológico, desde la ya veterana antropología aplicada hasta la más reciente negación postmodernista de la antropología como saber científico. En la práctica, según la mayoría de los indicadores, la disciplina sigue mostrándose en el tiempo presente como un producto espúreo del neoimperialismo, ejemplificado en los intereses académicos de los departamentos de antropología de las universidades estadounidenses específicamente. Según John 
Gledhill este hecho resulta evidente en su plena actualidad por la ineficacia política de la American Anthropological Association, que en los momentos de mayor radicalismo sólo llegó a denunciar la intervención norteamericana en Vietnam en términos tan genéricos como ineficaces, y siempre bajo el argumento tibio y equívoco de que los antropólogos no podían estar de acuerdo por motivos "profesionales" con la carrera genocida (Gledhill, 1994: 211). Más allá del colonialismo, el neoimperialismo parece seguir rigiendo los fundamentos de la antropología.

En la Unión Soviética mientras tanto la antropología social, desde la supresión de la Facultad de Etnología de Moscú en la época más dura del estalinismo, había recibido la consideración de "ciencia burguesa", y como tal estaba eliminada del campo del conocimiento. Ciertos debates, como el de la existencia de "feudalismo" en África, subsumían y mixtificaban cualquier posible antropología fundada en la alteridad, bajo la especie de la superioridad conceptual del materialismo histórico sobre todas las ciencias sociales e históricas. De otro lado y por razones un tanto diferentes, los países islámicos han rechazado de forma sutil igualmente la antropología social, por regla general como reacción contra una mirada metropolitana que les resultaba cuando menos sospechosa de colaboracionismo imperialista. Frente a la antropología alzaron la sociología como forma de conocimiento legítima, dentro de la cual pudieron reclamar una línea propia, que se iniciaría con la vindicación de Ibn Jaldún como padre de la sociología árabe, en el siglo XIV.

No ha sido cómoda, en general, la posición política de la antropología social. Acusada de colaboracionismo imperialista, rechazada abiertamente o colocada bajo sospecha, sus alternativas para volver a legitimarse han ido desde negar la condición de colaboracionista sin más, hasta añadir nuevos argumentos a las críticas sobre los fundamentos epistemológicos de la disciplina.

La antropología política no ha sufrido ninguna crítica particular en este contencioso, a pesar de ser acaso la subdisciplina más directamente implicada con el dominio colonial. El caso es que la antropología política en sentido estricto tiene pocos adeptos dentro del ya limitado mundo de la antropología social. Una de las últimas tratadistas, Joan Vincent, subraya que tras una encuesta realizada en 1983 entre los profesionales norteamericanos y británicos, no más de 250 de más de 3.000 en EE.UU. y menos de 100 de entre 500 en Gran Bretaña, manifestaron tener algún interés por la antropología política (Vincent, 1990). Su campo no aparece, pues, excesivamente estigmatizado por la crítica anticolonial, seguramente por no haber recibido un específico interés por parte de los mismos antropólogos, amén de sociólogos y politólogos. 
Más interés tiene averiguar las conexiones entre ideología, acción política y ciencia antropológico-social. Dejamos de lado lo referente al biologismo moderno o a la antropogeografía de los años treinta, por considerarlos periféricos o suficientemente debatidos. Una crítica, que en nuestra opinión habría que aceptar de Maurice Bloch respecto al conjunto de la antropología moderna, es la excesiva reificación de los fenómenos culturales como ritos; Bloch considera pertinente retomar la noción de ideología, cara sobre todo al materialismo histórico, para designar un campo de la intervención intelectual que no se agota sólo en lo mitológico y/o ritológico (Bloch, 1989). La ideología es sustancial a nuestra sociedad occidental, y más aún lo es la ideología política. Si bien la mayor parte de los profesionales se han mantenido alejados de la militancia política activa, sin descender a la arena competencial, por un inconfesado complejo de «astrónomos de las ciencias sociales», que diría Lévi-Strauss, en el terreno de las prácticas, la ideología política del antropólogo ha dejado una marca indeleble en su pensamiento científico.

La influencia política más importante ha sido, con gran diferencia respecto a otras, la del marxismo. El gran nudo para la antropología marxiana es el de la existencia de sociedades con y sin Estado, y sus tránsitos; para en época contemporánea, adecuado el marxismo a la realidad", pronunciarse por la democracia, como ideal político. Emmanuel Terray, por ejemplo, atacó virulentamente a Pierre Clastres, por su visión anarquizante y hobbesiana de las sociedades sudamericanas:

La democracia construida sobre este modelo (aristotélico) es incontestablemente una sociedad estática: a cada instante, una fracción de sus miembros allí ocupa una posición hegemónica. Por tanto la ley de la alternancia permite preservar la libertad y la igualdad. Según yo creo, Clastres nunca se ha pronunciado sobre este análisis de Aristóteles, y yo lo recuerdo; porque si se adopta su tesis de la 'gran partición' entre las sociedades primitivas y las sociedades con Estado, resulta que la democracia de Aristóteles está más cercana al despotismo y al totalitarismo que a la 'anarquía' de las comunidades salvajes (Terray, 1989: 10).

La politización ideológica de los debates entre los antropólogos políticos parece evidente. A nadie se le escapa que Robert Lowie creó su teoría de los "gérmenes" del Estado, por reacción contra Morgan, pero más en concreto por oposición al marxismo triunfante en aquellos momentos en Rusia, o que Terray adecua perfectamente sus argumentos a las posiciones momentáneas del partido comunista francés sobre la democracia.

Del lado estructuralista, Alfred Adler se expresó respecto a la antropología marxista en términos muy duros : L'ethnologie marxiste: vers un nouvel obscurantisme?» tituló un artículo polémico hacia Claude 
Meillassoux. Allí reivindicaba, frente a una visión marxista unilineal, que tomaba por modelos conceptos propios de las estructuras de Occidente -reproducción social, grupo doméstico, etc.-, los orígenes teóricos de la antropología:

Sobrepasando los esquemas de una evolución unilineal de las sociedades, dejando de lado el primado de la historia occidental como fuente de inteligibilidad de las instituciones sociales, no solamente valoran la idea de irreductibilidad de las culturas, de la riqueza y de la originalidad de las síntesis particulares que constituyen los unos y los otros (...), abren la vía a un radicalismo crítico en el cual todo etnólogo de hoy día se nutre o debiera nutrirse (Adler, 1976: 127).

A pesar de las críticas adversas, la antropología económica marxista tras los pasos de M. Godelier, C. Meillassoux o E. Terray, o más recientemente tras el materialismo cultural, ha servido de coartada y complemento ideológico a las insuficiencias del materialismo histórico originario, enfrentado a los nuevos horizontes cuantitativos y cualitativos que aportaba una cada vez más exhaustiva información etnográfica.

Curiosamente no ha existido una antropología política marxista contemporánea de similar importancia a la económica. Posiblemente debido a que algunos de los presupuestos de la antropología política chocaban de manera frontal con las aspiraciones igualitarias del pensamiento social del materialismo histórico. Nos referimos en concreto al clientelismo social y político. Alimentado por la filosofía de la Ilustración que preveía un horizonte igualitario para la Humanidad, y cegado por las fisiones horizontales de la sociedad de clases, el materialismo histórico y la antropología a él ligada, no acertaron a advertir la presencia de relaciones jerárquicas interiores a las clases. Cuando hablamos de marxismo nos referimos no sólo a una alambicada teoría social, económica y política, sino también a una determinada forma de ver los hechos sociales que ha marcado "l'imaginaire de sectores importantes de la población. Expondré un caso que me tocó experimentar personalmente: en el año 1988 el Ayuntamiento de la localidad almeriense de Macael me encargó escribir una etnografía e historia del movimiento obrero de la villa. Macael poseía una larga tradición de luchas obreras desde finales del siglo pasado, y ahora, con un ayuntamiento de izquierdas, parecía llegado el momento de escribir su historia de luchas y sufrimientos, felizmente superados. Sin embargo, los resultados de mi investigación, corta pero intensa, daban por resultado un horizonte de luces y sombras, donde se combinaba el heroísmo obrero con actos que podrían aparecer como vergonzantes, contemplados desde una visión idealizada de los movimientos sociales macaelenses (González Alcantud, 1990). En el horizonte de mi investigación había aparecido un 
factor clave, que el marxismo más o menos ortodoxo ha evitado durante largo tiempo: el clientelismo, que verticalmente iba de los patronos a los canteros en el terreno del trabajo y de la supervivencia diaria, y que éstos devolvían como "favores" a aquellos con su fidelidad "políticaw. La idealización de la memoria histórica y las heridas abiertas por la ciencia, llegan hasta hoy.

De la anécdota a la regla: el clientelismo político italiano, en especial el del Mezzogiorno, es asunto de la cotidianidad. Su omnipresencia ha atraído a una gran cantidad de antropólogos estrictamente políticos hacia el centro y sur de Italia. El fenómeno precisaba una explicación verosímil, que los pensadores marxistas italianos, como Antonio Gramsci, a pesar de su mucha lucidez no habían acertado a iluminar. Sobre el clientelismo rural italiano se han proyectado o deducido diversos conceptos: contrato diádico, amoral familismo, familismo exclusivista, etc. Todos ellos vienen a explicar que Italia, y fenómenos de cierta tradición histórica del género de la mafia, son deudores de la política de clientelas, a la que se adecuan tanto partidos políticos de corte conservador, del tipo de la Democracia Cristiana, como otros radicalmente igualitaristas en el terreno de los principios, como el partido comunista (White, 1980; González Alcantud, 1994 y en prensa). Si el sur de Italia ha servido de modelo para aplicar la teoría del clientelismo es porque en ella concurren ciertas características, como la violencia señorial ejercida históricamente a través de los capataces o "gabellottin. Pero la razón de fondo más importante es la existencia continuada, tras finalizar la Segunda Guerra Mundial, de una arena política competencial donde las facciones y partidos políticos deben concurrir para tomar parte en los beneficios del Estado central. El poder de cada facción depende casi en exclusiva de su red clientelar.

El golpe definitivo al pensamiento antropológico de izquierdas en relación con el ideal igualitario le ha venido del análisis de los proyectos radicalmente igualitaristas, y del fiasco utópico de su realización, contemplado con el detalle perturbardor de lo microsocial. Así John Davis desmenuzó las contradicciones insolubles de un régimen como el de Gadaffi, fundado de facto en una sociedad del hidrocarburo", similar en su monopolio sobre las fuentes de riqueza a las «sociedades hidráulicas" descritas por Wittfogel, el cual predicaba en lo ideal el protoanarquismo ideológico de la tercera vía", basada en la hegemonía política de los comités populares (Davis, 1987).

La imbricación entre saber antropológico, y en general todos los saberes de las ciencias sociales, y política ha sido especialmente intensa en aquellos países, como Libia o Marruecos, sometidos a un proceso de nacionalización interior como medio de superación del complejo colonial. 
Paul Pascon, sociólogo, etnógrafo y agrarista marroquí pasó, por ejemplo, siempre empujado por la coyuntura política interna de Marruecos, del marxismo militante a posiciones de "experto", "consejero" o "agente de desarrollo", "preocupado por la gestión leal de los proyectos de Estado, técnico trabajando en los márgenes de lo posible sin proyecto 'reformista' o 'revolucionario'. (Saaf, s.f.: 29). La determinación política sobre los investigadores sociales de los países excolonizados aparece mucho más intensa que el distanciamiento que Max Weber aventuraba para el científico y el político en la Europa de la primera mitad de este siglo (Weber, 1980).

La contradicción entre el ideal igualitario de la izquierda y el clientelismo efectivo no se ha salvado dentro del pensamiento marxista; ha sido la antropología social de orientación funcional, elaborada en centros universitarios sobre todo británicos, que implícitamente coadyuvaba a establecer una jerarquía de sociedades desarrolladas políticamente -el norte-, frente a otras "feudalizadas" —l Mediterráneo-, la que ha aportado elementos para superar el "impasse" teórico provocado por la presencia del clientelismo.

Finalmente, puede constatarse que en España la antropología política ha tenido y tiene poco predicamento entre los etnólogos. Son muy escasos los trabajos, surgidos por regla general con otra intencionalidad, que pudieran ser interpretados, no obstante, como colaterales a la antropología política. Así el ya mencionado y muy interesante de Carmelo Lisón sobre la monarquía de los Austrias, consagrado a la hermeneusis del poder, que podría englobarse en la antropología histórica política; de orientación igualmente histórica es el de Manuel Delgado sobre la quema de conventos en la Barcelona de los años treinta. El de Joseba Zulaika sobre el terrorismo de ETA se adecúa a los cánones de la antropología política funcionalista propiamente dicha.

Resulta paradójica esta ausencia de antropología política en la corta existencia de la antropología social española, ya que la mayor parte de nuestros etnólogos universitarios han jugado un papel estrictamente político en los últimos dieciocho años, laborando tras el concepto de identidad regional y sus derivaciones, una de las claves epistémicas de la transición política que se inició en 1975. Su lugar como dotadores de sentido intelectual a los regionalismos periféricos ha permitido que la antropología espanola haya recibido una atención preferente por parte de los gobiernos regionales, que consideraron que este saber era un aliado importante en la búsqueda de las nuevas o renovadas identidades (González Alcantud, 1992 y 1993). La inquietud social" manifiesta de algunos antropólogos fue orientada hacia el estudio de los sistemas económicos domésticos. La 
política, en una institución universitaria poco crítica y atravesada por el clientelismo asfixiante del espíritu de investigación, fue evitada conscientemente. Sólo ahora comienza a vislumbrarse la importancia de proceder a realizar la crítica de la antropología social regionalista, y a poner las bases para una antropología política que sintonice su discurso con lo mejor de la antropología social que se consagró hace veinte o treinta años al estudio de las sociedades políticas mediterráneas.

\section{José ANTONIO GONZÁlez AlCANTUd Universidad de Granada. Centro de Investigaciones Etnológicas «Angel Ganivet"}

\section{BIBLIOGRAFÍA}

ABÉlès, MARC, 1983: El lugar de la política, Barcelona: Mitre.

- 1990: Anthropologie de L'Etat, Paris: Armand Colin.

ADLER, ALFRED, 1976: "L'Ethnologie marxiste: vers un nouvel obscurantisme?", L'Homme, XVI, 4.

Baduel, PIERre Robert, 1991: "Le front de L'Etat. Eléments pour une approche comparative autour de la Méditerranée., Revue du Monde Musulman et de la Mediterranée, 59, 128-163.

Bailey, F. G., 1965: "Decisions by Consensus in Councils and Comittees. With special Reference to Village and Local Government in India*, en M. GluckMan y F. EGGAN (eds.), Political Systems and the Distribution of Power, Edinburgh: Travistock, 1-20.

- 1990: Strategems and Spoils. A Social Anthropology of Politics, Oxford: Blackwell.

BALANDIER, GEORgES, 1975: Antropo-Lógicas, Barcelona: Península.

- 1991: Anthropologie politique, Paris: PUF, 2. ed.

BARÉ, JEAN-FrANÇOIS, 1984: "Fantômes de la violence: énigmes tahitiennes", Etudes Rurales, 95-96, 23-46.

Bloch, MAURICE, 1975: “Introduction", en M. Bloch (ed.), Political Language and Oratory in Traditional Society, London: Academic Press, 13-18.

- 1989: Rituel, History and Power, London: London School of Economics.

Cannadine, D. and Price, S. (comps.), 1987: Ritual of Royalty. Power and Ceremonial in Traditional Societies, Cambridge: Cambridge University Press.

Caro Baroja, Julio, 1989: Terror y terrorismo, Madrid: Plaza y Janés, $2 .^{*}$ ed.

CASSIRER, ERNEST, 1985: El mito del Estado, México: FCE, 5. ed.

ChAGNON, NAPOlEON A., 1992: Yanomamö, Stanford University.

Clastres, PIERRE, 1987: Investigaciones en Antropología politica, Madrid: Gedisa.

DAvIS, JOHN, 1987: Libyan politics. Tribe and Revolution, London: I.B. Tauris.

Delgado Ruiz, Manuel, 1993: La ira sagrada. Anticlericalismo, iconoclastia y antirritualismo en la España contemporánea, Barcelona: Humanidades.

Dumont, Louis, 1966: Homo bierarcbicus, Paris: Gallimard (trad. castellana Madrid: Aguilar, 1970). 
EASTON, DAvid, 1959: „Political Anthropology", Biennial Review of Antbropology, 232 y ss.

- 1969: Esquema para el análisis politico, Buenos Aires: Amorrortu.

Evans-Pritchard, E. E., 1977: Los Nuer, Barcelona: Anagrama.

- and FORTEs, M. (eds.), 1940: African Political Systems, London: Oxford University Press.

Fallers, Lloyd A., 1965: Bantu Bureaucracy. A Century of Political Evolution among the Basoga of Uganda, Chicago: Chicago University Press, 2. ed.

GILMORE, DAVID, 1983: Agression and Community. Paradoxes of culture Andalusian, Yale University Press.

GledHILl, JoHN, 1994: Power and its Disquises. Anthropological Perspectives on Politics, London-Colorado: Pluto Press.

Gluckman, Max, 1956: Custom and Conflict in Africa, Oxford: Blackwell.

GODELIER, MAURICE, 1969: Las sociedades primitivas y el nacimiento de las sociedades de clases segün Marx y Engels, Bogotá: La Oveja Negra.

Gomes DE SILVA, 1987: L'identité volée, Bruxelles: Université Libre de Bruxelles.

GoNZÁlez ALCANTUD, José ANTONIO, 1990: Canteros y caciques en la lucha por el mármol. Macael: etnologia e historia oral, Almería: Diputación Provincial.

- 1992: "Andalucía: invención del país y realidad etnográfica", Historia y Fuente Oral, 8, 7-27.

- 1993: "Antropología andaluza: entre el ensimismamiento y el ruralismo", Antbropologica, 7-12, 211-222.

- 1994: "El clientelismo social y político en las sociedades mediterráneas", en KOTTAK (ed.), Antropología. Una interpretación sociocultural de la diversidad bumana, Madrid: McGraw-Hill, 261-276.

- en prensa: "Jerarquía versus igualdad. El clientelismo político desde la antropología", en A. ROBLES EGEA (comp.), El clientelismo político, Madrid: Siglo XXI.

GOODY, JACK, 1971: Technology. Tradition and the State in Africa, Oxford: Oxford University Press.

GORDON CHILDE, VERE, 1965: La evolución de la sociedad, Barcelona: Ciencia Nueva.

HART, DAVID M., 1976: The Aith Waryaghar of the Moroccan Rif, The Arizona University Press.

- 1994: "La organización socio-política de los beréberes marroquíes", en R. RAHA AHMED (ed.), Imazighen del Magreb entre Occidente y Oriente, Granada, 117-132.

HEUSCH, LUC, 1972: Le roi ivre ou l'origine de L'Etat, Paris: Gallimard.

Huizer, GerRIT, 1979: "Anthropology and Politics: From Naiveté Toward Liberation", en G. Huizer and B. Manheim (comps.), The Politics of Anthropology. From Colonialism and Sexism. Tourard a View from Bellow, The Hague: Mouton.

KANTOROWICZ, ERNEST H., 1985: Los dos cuerpos del rey. Un estudio de teología política medieval, Madrid: Alianza.

Kertzer, David, 1988: Ritual, Politics and Pourer, Yale University Press.

LEACH, EDMUnd R., 1970: Political Systems of Highland Burma, London: Atholone Press (trad. castellana Barcelona: Anagrama, 1976).

- 1977: Custom, Law and Terrorist violence, Edinburg University.

LÉvi-Strauss, Claude, 1981: Las estructuras elementales del parentesco, Barcelona: Paidós.

LEWELLEN, TED C., 1985: Introducción a la antropología política, Barcelona: Bellaterra. LINDHOLM, CHARLES, 1992: Carisma, Madrid: Gedisa. 
Lisón TOlOSANA, CARMelo, 1991: La imagen del rey. Monarquía, realeza y poder ritual en la Casa de los Austrias, Madrid: Austral.

LOWIE, ROBERT H., 1927: The Origin of the State, New York: Russell and Russell.

- 1979: La sociedad primitiva, Buenos Aires: Amorrortu.

Macfarlane, Graham, 1988: "Violencia en la Irlanda del Norte rural: modelos científicosociales, explicaciones populares y variantes locales", en D. Riches (comp.), El fenómeno de la violencia, Madrid: Pirámide, 251-276.

MAINE, H. S., 1861: Ancient Law, London: John Murray.

MAIR, LUCY, 1977: El gobierno primitivo, Buenos Aires: Amorrortu.

MASQUERAY, ÉmILE, 1983: Formation des cités chez les populations sédentaires de L'Algérie. Kabyles du Djurdjura, Chaouïa de L'Aourâs, Beni Mezah, Aix: Ed. Facsimil Edisud [1885].

MONTAGNe, ROBERT, 1973: The Berbers. Their Social and Political Organization, London: Frank Cass.

MORGAN, LEWIS H., 1975: La sociedad primitiva, Madrid: Ayuso.

NichOLAS, RALPH W., 1965 .Factions: a Comparative Analysis", en M. GluCKMAN and F. EgGan (comps.), Politicals Systems and the Distribution of Power, Edinburgh: Tavistock.

NORBECK, EDWARD, 1977: "A Sanction for Authority: Etiquette, en R. D. FogELSON and R. N. ADAMs (eds.), The Anbropology of Power, New York: Academic Press.

RACHIK, HASSAN, 1992: Le sultan des autres. Rituel et politique dans le Haut Atlas, Casablanca: Afrique Orient.

SaAf, AbDallah, s. f.: Politique et savoir au Maroc, Rabat: Smer.

SAHLINS, MARShall, 1977: Economia de la edad de piedra, Madrid: Akal.

SERVICE, ElMAN R., 1984: Los origenes del Estado y de la Civilización, Madrid: Alianza. Terray, Emmanuel, 1987: "Le débat politique dans les royaumes de L'Afrique de L'Ouest. Enjeux et formes", Revue Française de Science Politique, 38, 5.

- 1989: «Une nouvelle anthropologie politique?", L'Homme, 110.

VinCENT, JoAn, 1990: Anthropology and Politics. Visions, Traditions and Trends, University of Arizona Press.

WEBER, MAX, 1980: El político y el científico, Madrid: Alianza.

White, Caroline, 1980: Patrons and Partisans. A Study of Politics in two Soutbern Italian Communitys, Cambridge University Press.

WINCKLER, EDWIN, 1969: :Political Anthropology", Biennial Review of Anthropology. WITTFOGEL, KARL, 1957: Oriental Despotism, New Haven: Yale University Press. ZulAIKA, JOSEBA, 1990: Violencia vasca. Metáfora y sacramento, Barcelona: Nerea.

La antropología y la política se han relacionado epistemológicamente en cuatro niveles estructurales: espacio, tiempo, conflicto y rito. En ellos se cruzaron, opusieron y sintetizaron las aportaciones de muchos de los antropólogos que han constituído la antropología política como subdisciplina. Central a ésta y a todas sus corrientes -desde la evolucionista hasta la procesual-, ha sido la delimitación del campo mínimo significante de emergencia de lo epolítico. Por otro lado, la antropología política es una práctica intelectual estrechamente ligada a las vicisitudes de la política diaria. 
Anthropology and politics have been epistemologically related at four structural levels: space, time, conflict and rite. Some anthropologists have made contributions to these four levels, turning political anthropology into a subdiscipline. The delimitation of the minimal space for the emergency of the 'political' has been central to all the orientations of political anthropology - from the evolutionist to the processual-. On the other hand, political anthropology as an intellectual practice is deeply influenced by the day-to-day political vicissitudes. 